LA-5572-MS

Informal Report

Design and Development of a Combination Impulse Transducer 
This report was prepared as an account of work sponsored by ths United States Government. Neither the United States nor the United States Atomic Energy Commission, nor any of their employees, nor any of their cinntrac. tors, subcontractors, or their employees, makes any warranty, express $\mathrm{or}$ implied, or assumes any legal liability or responsibility for the accuracy, eכn:pleteness or usefulness of any information, apparatus, product or prosess olisclosed, or represents that its use would not infringe privately owned rights.

In the interest of prompt distribution, this LAMS report was not edited by the Technical information staff.

Printed in the Uniled States of America. Available trom

National Technical Information Service

U.S. Department of Commerce 5285 Port Royal Road

Springlield, Virginia 22151

Price: Printed Copy \$4.00 Microtiche $\$ 1.45$ 
LA-5572-MS

informal Report

UC-37

Reporting Date: March 1974

Issued: April 1974

\section{Design and Development of $\alpha$ Combination Impulse Transducer}

by

V. S. Starkovich

E. L. Stephani

E. V. Hawkins

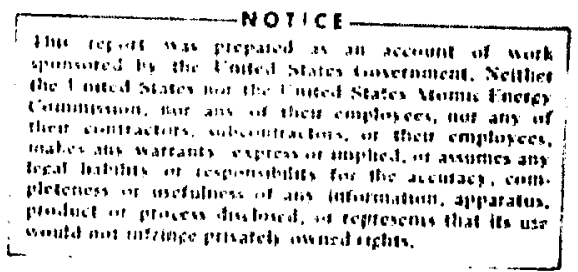


DESIGN AND DEVELOPMENT OF $\wedge$ CONBINATION IMPULSE TRANSDUCER

by

V. S. Starkovich, E. I. Stephanl, and E. V. llawkins

ABSTRICT

An impulse cransducer gauge capable of providing both active and passive measurements of $x$-ray-produced blowoff impulse is described. The gauge is a combination of the compatible features of the Philco-ford passive wirecutter gauge and the LASL Probe Veloclty Transducer. The transducer has been used with success on three underground nuclear tests.

\section{INTRODUCTION}

One of the inherent problems associated with existing active and passive ispulse gauges used in the measuremenc of $x$-ray-produced blowoti inpulse In underground effects tests is the reliance upon elelice sigaal transmission during the test of postshot recovery of the siuge. The most rellable mechod is othe which would not be solely dependent on either method, but combine the compatible featurcs of existing active and passive impulse measureanent techniquos. In addition, the systes should be limited in slac to pernit its uye in cassetees, be reliable in soverc nurlear rallation chvironments, and produce active signals that are cartpatible witi a variety of relatively inexpensive stgnal recurdling techniques.

An impulso transducer which incorporates the compatible features of the probe Volucity transducer and the Philco-ford Corp. passive wirecutter gauge lias been developed and tested (sca Fifi. 1). The active part of the saupe does not require active calibrat ton and produces a characteristie, lowfrequeney signal which lends itself to imneditec data reduction. The dynamic range of tho nctive portion of the gauge is between 0.02 (0.1 k: 200 $\mathrm{mo} / \mathrm{s})$ and $40(1 \mathrm{~kg} \mathrm{Q} 40 \mathrm{~m} / \mathrm{s}) \mathrm{N} \cdot \mathrm{s}$, or from approximatcly 10 to $20000 \mathrm{~N} \cdot \mathrm{s} / \mathrm{ta}^{2}$ for cormonly usced arcos and massics. In the Comblnation Impulac Transilucer

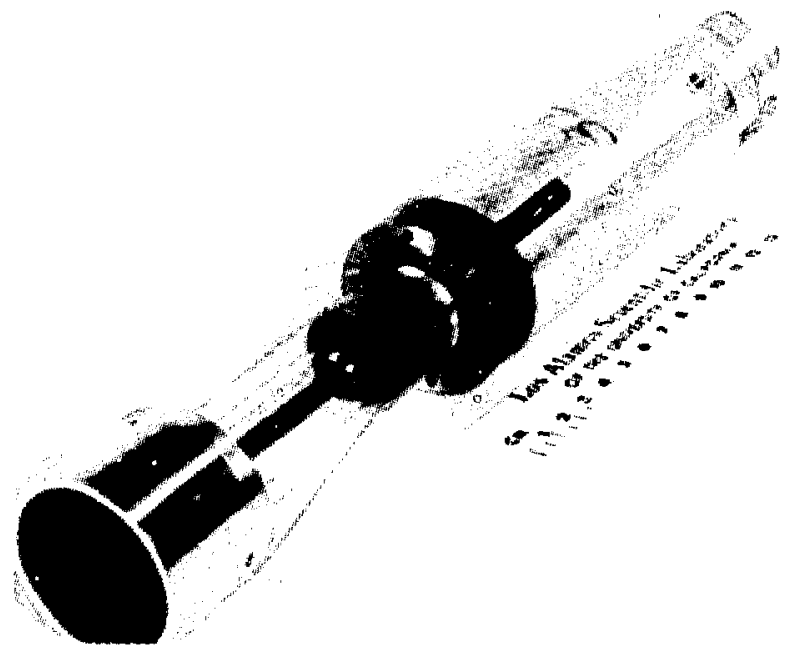

Fig. 1. Combination Impulse Transducer (CIT).

(CIT), the Inductive probe' has been replaced by an activnted piekup coll. The eliaracteristic shape and relat lucly low frequency $(1-5 \mathrm{klla})$ of the output signal simplifies reduction of the shot data and pormits the use of tho shiclded cwisted pair cable for sigmal transmisbion to distant recordlng facil1ciess.

The passifive nare of clue transducer ls a modlfied wirecucter gange whobe rotor is cringered by the melt dan of a thin aluminum or copper rtbbon exposed to the $x$-ray fluched. By making the trigner 
Independent of the translational energy, the low impulse threshold of the gaug: is reduced to approximately $0.01 \mathrm{~N} \cdot \mathrm{s}$ without compromising the dynamic range of the passive system. The dynamic range of the passive part extends from this low limit to an upper $1 \mathrm{fmit}$ of $2.5 \mathrm{~N} \cdot \mathrm{s}$.

Although each rotor is calibrated separately, redurant active and passive calibration data from the assembled gauge provide an internal conststency check on gauge performance. The active part records times at known positions and the passive part records positions at known times; therefore, the active and passive data complement each other. Data from the active part of the CIT gauge are determined directly from oscilloscope or oscillograph tape playbacks. Subsequent to recovery, the wire lengths are measured and combined with the preshot rotor calibration data to achieve a passive measurement of the velocity of the moving assembly.

\section{THEORY OF OPERATION}

A schematic of the CIT gauge is shown in Fig. 2. The principal components of the active part of the transducer are: (a) a steel shaft into which equally spaced rings have been machined, and (b) a radio-frequency-excited Inductive pickup coil to sense the passing of each ring. The main components

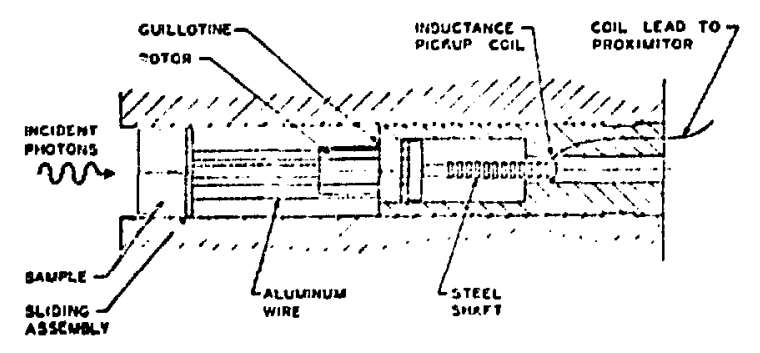

F18. 2. Schenatic of the Combination Impulse Transducer (CIT). of the passive part of the gauge are: (a) a sliding assemb!y which holds the test sample and serves as a frame to hold seven wires strung parallel to the direction of motion, (b) a housing which provides a low friction translation of the sliding assembly, and (c) a spring-driven rotor with a guillotine that sequentially cuts the wires during the translation of the sliding assembly. The Inductive pickup coil used in the transducer consists of a flat $15-\mathrm{mm}$ coil of $0.08-\mathrm{mm}$ copper wire ( 60 turns) located riear the end of the gauge housing. For Insulation and mechanIcal rigidity, this pickup coll is mounted within a cylindrical tefion shell. Figure 3 is a block diagram of the electronics zequired for the active portion of the CIT gauge. In addition to the pickup coil, an oscillator-demodulator circuit, power supply, and line driver amplifier are used with signal recording equipment. A positive and negative 15-V dc excitation from the power supply is applied at the oscillator-demodulator (Bently Proximitor) 1:iput terminals. The proximitor converts this voltage Into a 1-MHz signal, which is applied to the pickup coll through a coaxial cable. The pickup coll radiates this signal as an electromagnetic field into the region along its axis. If there is no nearby conductive material to intercept the field, such as a space between rings, there is little loss of the signal. However, when a conductive surface

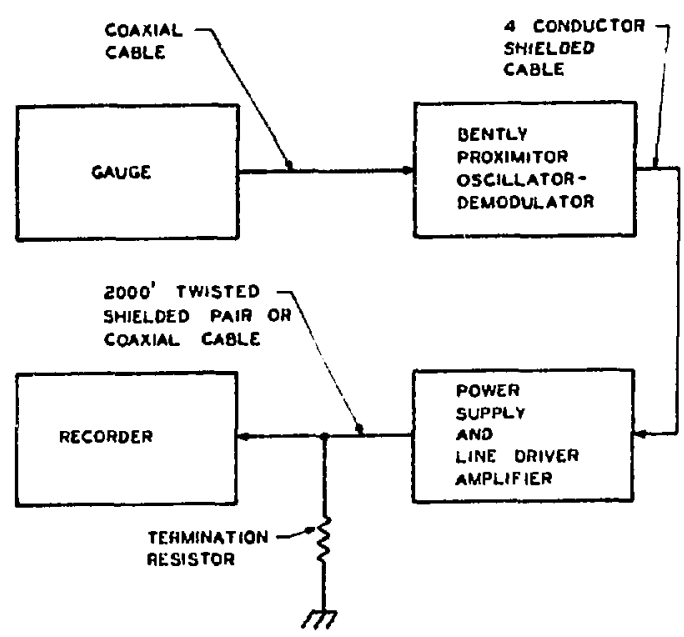

F1g. 3. Block diagram of electronics for a typical fiold transducer system. 
approaches the inner diameter of the pickup coll, eddy currents are generated on the surface of the material and power is absorbed (i.e., the coil is detuned). The voltage spike corresponding to the passing ring can be measured directly or amplified and transmitted over low quality signal cable to distant recording facilities. The frequency response of the system is about $10 \mathrm{kHz}$. Figure 4 is a typical signal from the active part of the CIT gauge.

Because the rings on the shaft are spaced at about 5-m intervals, the electronic system is capable of handling velocities as high as $50-\mathrm{m} / \mathrm{sec}$ (1.e., $5 \min \times 10 \mathrm{kHz}$ ), which is considerably above the $15 \mathrm{~m} / \mathrm{sec}$ velocity at which shaft resonance becomes noticeable. A total translation distance of $50 \mathrm{mo}$ is used, which corresponds to about 10 voltage spikes.

Knowing the ring spacing and mass of the sliding assembly as well as the exposure area, one need only record the periodic change in the signal levels as a function of tine to determine the impulse/area imparted to the sample. Because the pickup coil surrounds the machined shaft, signal output is insensitive to any lack of concentricity of the shaft and the coil; however, non-linear effects such as unequal signal amplitude are of no concern. Only the location in time of each voltage peak is needed to determine the rod velocity. This feature assures a good signal resolution under severe nuclear radiation and cable notse conditions.

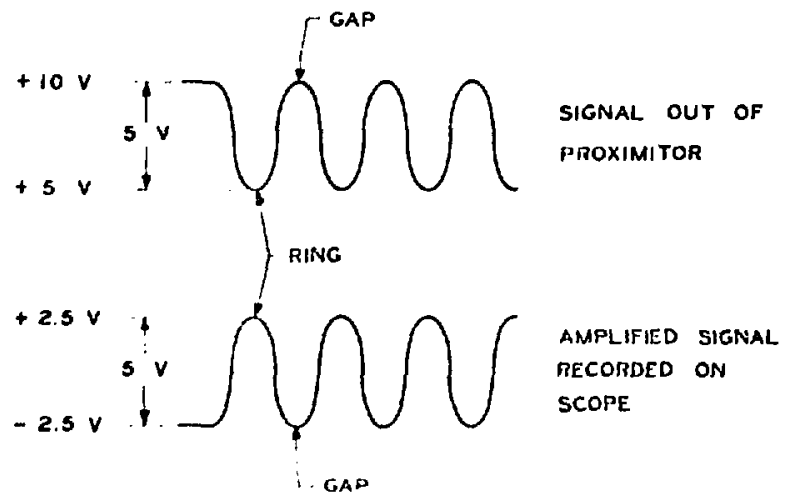

Fig. 4. Schemat1ce of 6ignal produced by (a) proximitor, (b) Ilne drlver.
The part of the electronics system between the plckup coll and the proximitior package consists of a tuned clrcuit, and to get maximim signal output the lengch of the extension cable muist be matched to the number of turns of wire in the pickup coil. The variation of the output signal anplitude as a function of the number of turns for several cable lengths is shown in Fig. 5.

For the passive part of the CIr gauge, calibratiou of the rotor is necessary so that the times corresponding to the cutting of the wires are known. The cut wire lengths provide a permanent and easil; measured record of the translation history of the sliding assembly. The optimum translation velocity is approximarely $2.5 \mathrm{~m} / \mathrm{sec}$, and is achieved by adjusting the weight of the sliding assembly. At this optimum velocity, all seven wires are cut in a time just sufficient for the sliding assembly to translate the full available $50 \mathrm{~mm}$. The use of multiple wires affords a dynamic range such that reasonably accurate measurements can be achleved as long as the actual velocity is within 0.1 to 4.0 times the optimam velocity. The permanent record provided in the cut wire lengths is achieved before ground shock arrival, and is not affected by

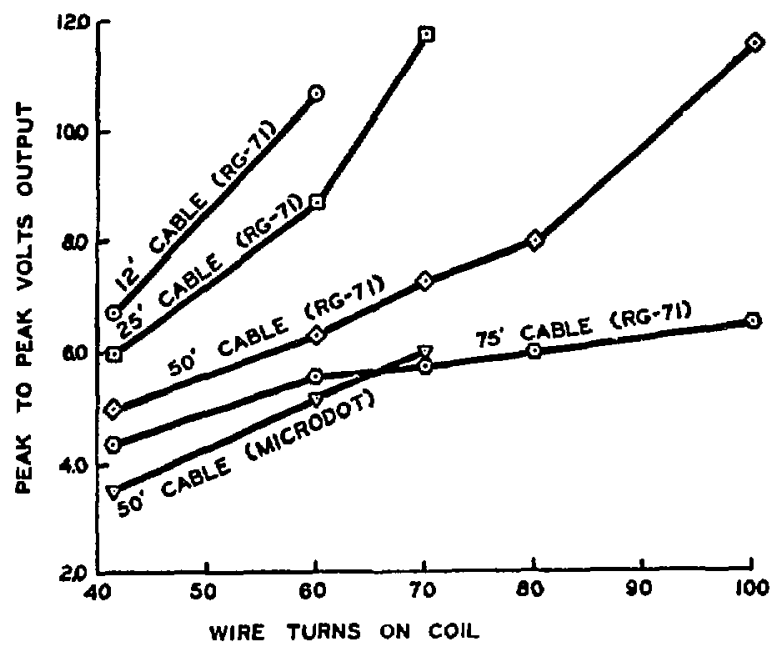

Fig. 5. Variation of signal amplitude as a function of the number of turns of wire in the pickup coil. 
late-time debris or suisequent handling. Because the gauges are usually recovered and reusable, gauge calibration and operability can be verified both before and after the test.

\section{DETAILS OF CONSTRUCTION}

A. Sliding Assembly

A cutaway view of the gauge assembly is shown in Fig. 6. The sliding assembly is the part that translates following the delivery of an impulse to the material specimen. It consists of the sample cup, the aluminum front and base plates that serve as a frame for the seven aluminum wires, and the steel shaft into which equally spaced rings have been machined. During the assembly of the gauge, the front and base plates are attached to the steel shaft after the latter is inserted Into the central housing. The plates are keyed to the shaft to assure alignment of the wire hole positions. After the rotor is cocked and locked into position, the sluminum wires are threaded through their respective holes in the front plate, locked into place by attachment of the sample cup, and threaded through their respective holes in the central housing. They are then positioned in the appropriate notches in the circumference of the base plate and locked in a taut configuration by screws and washers on the back of the base place. The steel shaft contains 12 rings with a nominal 9.50-mm-0.d. and 6.35min i.d., a ring spacing of $4.83 \mathrm{~mm}$, and a ring thickness of $1.27 \mathrm{~mm}$. The ball bushings which support the sliding assembly (Thomson Industries Mode1 A-4812) are lubricated with a mixtare of $50 / 50$ (by

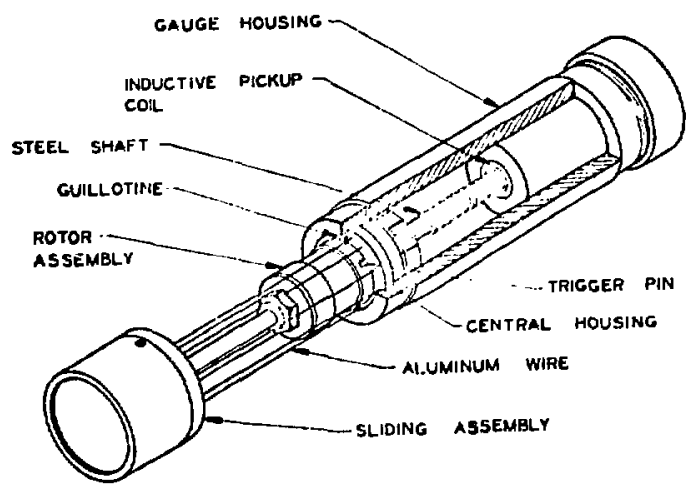

Fig. 6. Cutaway view of the Combination Im:pulse Transducer (CIT). volume) indium powder and molybdenum disulfide, diluted with Octoil-s diffusion pump ofl to minimize friction in a high vacuum while maintaining the gauge tolerance to lateral vibrations.

B. Gauge Housing Assembly

The gauge housing is the stationary part of the gauge that is rigidly attached to the vacuum pipe bulkhead or cassette. Its principal components are an inductive pickup coil, spring-loaded trígger pin, and Insulated BITC connector. The excited inductive pickup coij which senses the passing of each ring consists of approximately 60 turns of $0.08-\mathrm{mm}$ copper wire wound within a $15 \mathrm{~mm}$ diam $x$ 10-mm-long $x$ 2-mm-thick teflon cylinder. Wires from the coil pass through the rear of the gauge housing via the insulated BNC connector. When the gauge is assembled and cocked, the spring-loaded trigger pin is held in position by an aluminum restraining ribbon. When the aluminum restraining ribbon is melted by the $x$-ray flux, the trigger pin is projected approximately $2.5 \mathrm{~m}$ by the spring, and the rotor is released. A small bronze bushing is placed in the central housing to reduce the drag on the pin.

\section{Rotor Assembly}

A picture of the rotor assembly, central housing fixture, steel shaft, and base plate is shown in Fig. 7. The wires of the sliding assembly pass through holes in the base of the central housing assembly and are cut by the blade as it sweeps flush

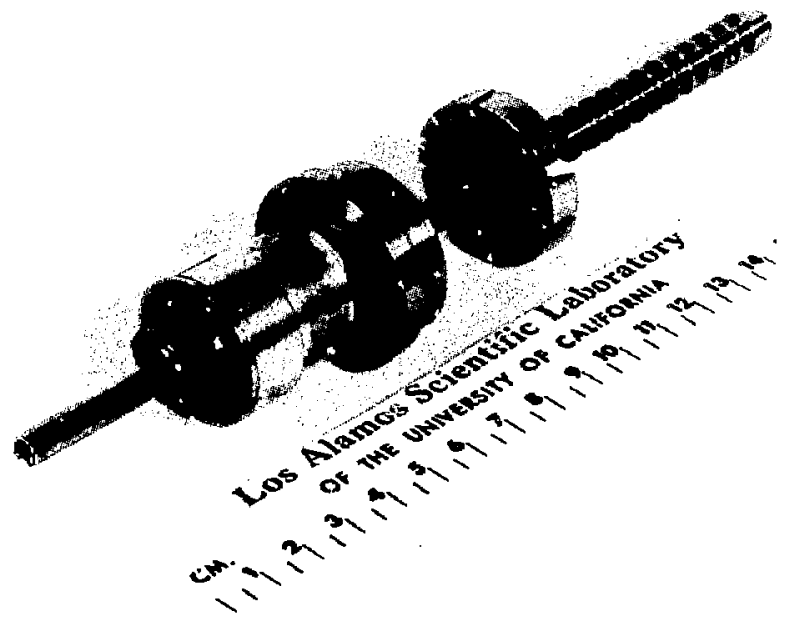

Fig. 7. Rotor assembly, central housing fixture, steel shaft and base plate. 
across the surface where the wires exit. The rotor assembils rides on needle bearings (Torrington, B105) which are held in place by a snap rirg. The cutting blade, which is made from high carbon steel, rides flush on the frort surface of the central housing unit. The spiral, tape-driven spring is made of $0.34-\mathrm{mm}$ stainless steel tape; 7.92-mm wide and $0.50-\mathrm{m}$ long. This particular configuration was chosen to improve gauge reliability and accuracy. D. Safety Pin Provisions

To minimize sample damage and to improve reliability, provisions for safety pins were incorporated into the design. Both the trigger safety pin and the sliding assembly safety pin consist of threaded shafts inserted through holes in the rear of the gauge housing adjacent to the insulated BNC connector. Upon completion of field installation, the sliding assembly safety pin is removed from the gauge, and the trigger safety pin backed off from the spring-loaded trigger. Although occasional modifications will be made and documented, further details of the CIT gauge construction as they presently exist are available in LASL Dwg. Nos. $74 \mathrm{Y}-172163$ D1-D5.

\section{ROTOR CALIBRATION PROCEDURE}

As indicated earller, the active part of the CIT gauges does not require in-field calibration. Only the exposure area, sliding assembly mass, and ring spacing are required to obtain impulse/area from the time-resolved output signal. The impulse measurements made with the passive wirecutter part of the gauge are, however, dependent upon rotor cutting times. Although this parameter is approximately constant from one rotor to the next, each rotor is calibrated to assure that an accurate impulse measurement is obtained.

To provide a fast, accurate method of deterwining wire cutting times and uncertainties in rotor operation, a rotor calibration system, patterned after the Philco-Ford method ${ }^{2}$, was established. The purpose of the system is to measure the times of blade arrival at each hole relative to the first hole. By determining these time intervals, the calibration can be combined with the shot data and processed by computer.

A schematic of the rotor calibration setup with the instrumentation required for immediate data readout is shown in Fig. 8 . By positioning a photo diode behind each wire hole in the central housing and illuminating the assembly with an intense light source, negative gating pulses are obtained as the guillotiue interrupts the light to the respective diode. The gating pulses are used to trigger a digital counter. The six time intervals measured during the calibration are referenced from wire hole No. 1 , yielding the time for rotor travel from hole No. 1 to each of the remaining ho?es.

Although wires are not cut in a vacuum during the calibration procedure, uncertainties in rotor angular velocity due to these and other effects are discussed in the following section.

\section{v. DYNAMIC IMPULSE MEASIJREMENTS \\ A. Results}

As part of the design and development process a number of CIT gauges have been dynamically tested over an impulse range of $7 \times 10^{-2}$ to $1 \mathrm{~N} \cdot \mathrm{s}$. A specially designed air rifle and bullet-velocity measuring system were employed to compare the impulse imparted to the cup by the bullet, $I_{B}$, with the impulses measured by the active probe, $I_{A}$, and the passive wirecutter part, $I_{W C}$. Such tests have been very useful in improving gauge design by eliminating systematic uncertainties and providing experimenters with sufficient data to make a reasonable error analysis of passive and active

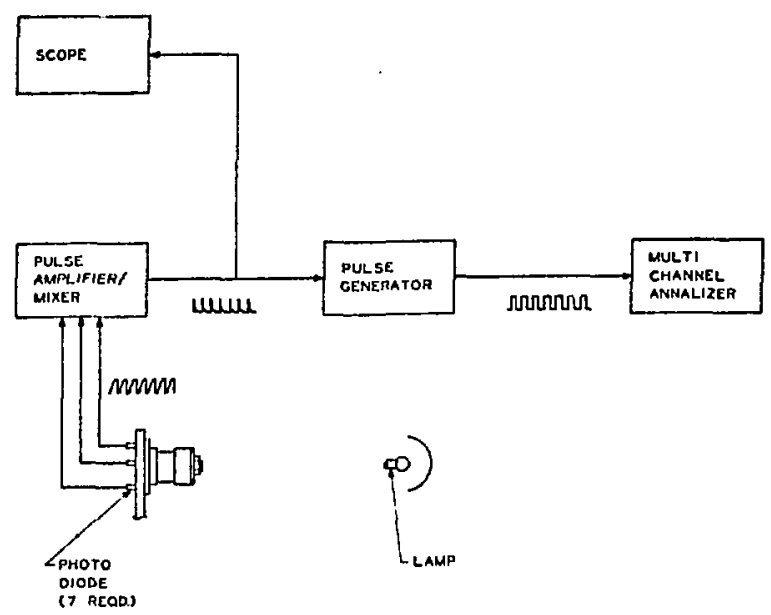

Fig. 8, Schemat 1.c of hardware used for rotor callbration. 
Impulse results. Representative signals recorded during these tests are presented in Fig. 9, with representative Impulse results presented in Table $I$. A schematic of the dynamic calibration system used In the above measurements is shown in Fig. 10.

Single and multiple barrel cassettes typical of those employed in undergr ound tests are shown iil FIgs. 11 and 12, respectively. For the multiple barrel cassettes, exposure dtameters of $13 \mathrm{~cm}^{2}$ have been used with a center-to-center gauge spacing of $50 \mathrm{~mm}$. Table II presents a comparison of active and passive data obtained from a recent underground test.

\section{B. Uncertainties}

Experimental errors in the determination of high impulse values $\left(>10^{-1} \mathrm{~N} \cdot \mathrm{s}\right)$ from the active part of the CIT gauge arise primarily from uncertainties in digitization of the raw signal traces and oscilloscope time calfbration traces. This error is generally less than $\pm 2 \%$. The marked increase in spacing for low impulse values between the signal blips (see Fig. 9) as a function of time indfcate a decrease in rod velocity due to frictional effecis between the steel shaft and ball bushIngs, alignment screw drag, and wire drag. Uncertainties in impulse measurement arising from friction are approximately $t 5 \%$ for impulses between $5 \times 10^{-2}$ and $1 \times 10^{-1} \mathrm{~N} \cdot \mathrm{g}$, approximately $\pm 10 \%$ between $3 \times 10^{-2}$ and $5 \times 10^{-2} \mathrm{~N} \cdot \mathrm{s}$, and as high as \pm $30 \mathrm{z}$ for tmpulses between $2 \times 10^{-2}$ and $3 \times 10^{-2} \mathrm{~N} \cdot \mathrm{s}$.

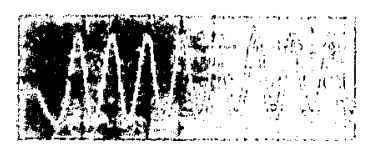

$\ldots+, \ldots,+\ldots$

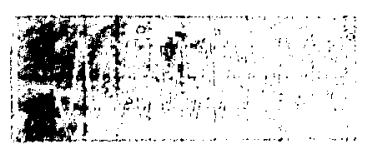

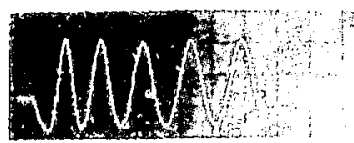

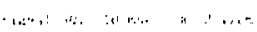

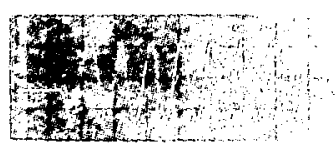

AIR RIFLE DYNAMIC TESTS

\begin{tabular}{llll} 
Run No. & $I_{B}{ }^{*}\left(10^{-3} \mathrm{~N} \cdot \mathrm{B}\right)$ & $I_{A}\left(10^{-3} \mathrm{~N} \cdot \theta\right)$ & $\frac{I_{W G}\left(10^{-3} \mathrm{~N} \cdot \mathrm{B}\right)}{51}$ \\
\cline { 2 - 3 } & $73.2 \pm 0.7$ & $53.3 \pm 2.7$ & $51.6 \pm 1.5$ \\
50 & $74.9 \pm 0.8$ & $52.3 \pm 2.6$ & $77.5 \pm 1.3$ \\
52 & $78.7 \pm 0.8$ & $66.7 \pm 3.3$ & $119.2 \pm 3.8$ \\
48 & $118.9 \pm 1.2$ & $113.0 \pm 3.4$ & $126.2 \pm 1.7$ \\
45 & $138.4 \pm 2.4$ & $124.1 \pm 3.7$ & $139.7 \pm 4.1$ \\
44 & $139.8 \pm 1.4$ & $131.2 \pm 3.9$ & $126.3 \pm 1.2$ \\
54 & $149.7 \pm 1.5$ & $125.4 \pm 3.8$ & $173.3 \pm 4.2$ \\
24 & $158.4 \pm 1.6$ & $148.0 \pm 4.4$ & $144.3 \pm 2.0$ \\
47 & $159.0 \pm 1.6$ & $140.1 \pm 4.2$ & $164.4 \pm 1.4$ \\
46 & $161.3 \pm 1.6$ & $151.8 \pm 4.6$ & $161.0 \pm 1.4$ \\
53 & $230.1 \pm 2.3$ & $161.4 \pm 4.8$ & $333.3 \pm 2.8$ \\
22 & $338.1 \pm 3.4$ & $312.4 \pm 9.4$ & $316.5 \pm 33.2$ \\
23 & $341.8 \pm 3.4$ & $335.8 \pm 10.1$ & $317.8 \pm 26.8$ \\
36 & $361.0 \pm 3.6$ & $347.0 \pm 10.4$ & $562.3 \pm 97.6$ \\
55 & $708.5 \pm 7.1$ & $653.3 \pm 19.6$ & $772.3 \pm 76.3$ \\
42 & $806.0 \pm 8.1$ & $739.7 \pm 22.2$ & $746.5 \pm 58.9$ \\
37 & $835.1 \pm 8.4$ & $739.7 \pm 22.2$ & $847.7 \pm 4.7$ \\
41 & $859.2 \pm 8.6$ & $863.1 \pm 25.9$ & $909.2 \pm 8.4$ \\
40 & $866.0 \pm 8.7$ & $829.7 \pm 24.9$ & $900.4 \pm 6.4$ \\
38 & $888.2 \pm 8.9$ & $883.8 \pm 26.5$ & $750.0 \pm 69.4$ \\
39 & $901.9 \pm 9.0$ & $852.0 \pm 25.6$ &
\end{tabular}

* 12 uncertainty has been agsigned to these values.

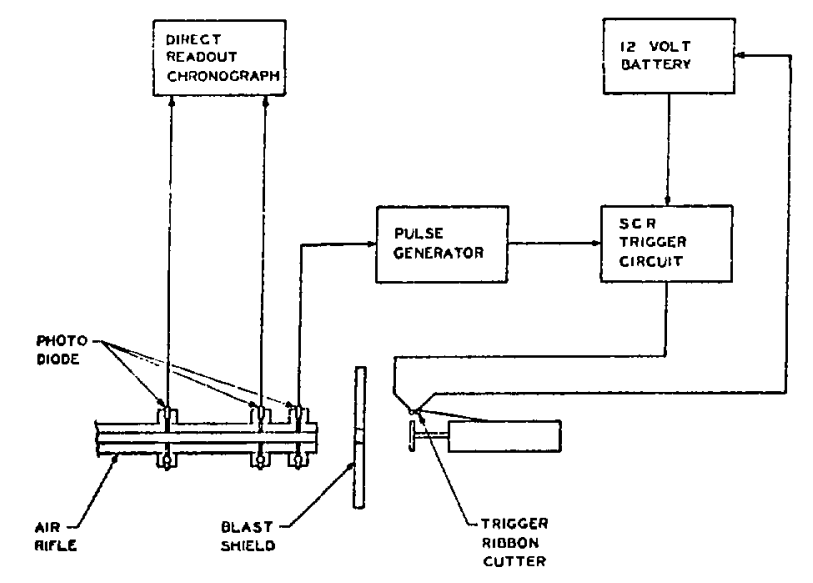

E1B. 9. Representative signals recorded during dynamic calibration tests.
Fig. 10. Schematic of the dynamic calfbration system. 


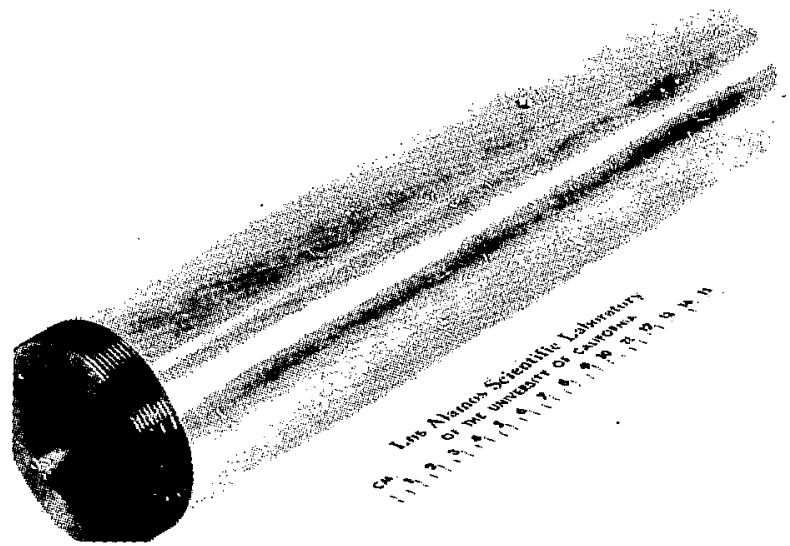

F1g. 11. Single barrel cassette.

Because neither the active nor passive portion of the CIT gauge depend upon a low impulse trigger, frictional effects determine the low impulse threshold of the gauge.

A technique using a Validator (Brown and Sharpe Model 100) has been developed to determine the wire lengths to high precision. The system involves spectal fixtures which hold the steel shaft and backing plate in position while maintaining constant tension in the wire with the aid of a counterwelght and air bearing. Although an on-line

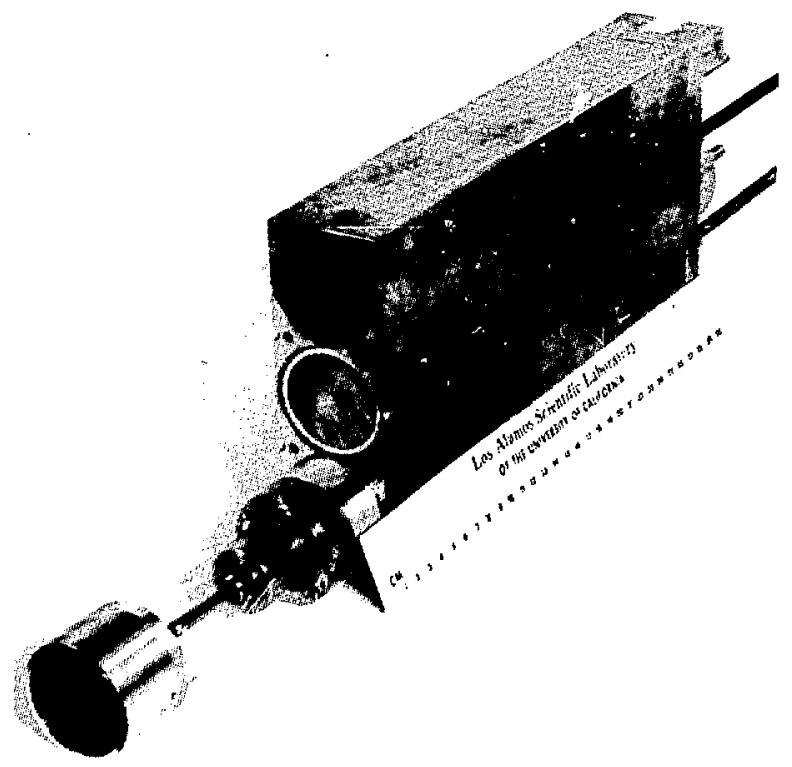

Fig. 12. Multiple barrel cassette with impulse gauge.

PDP $/ 8 \mathrm{C}$ computer prints out the wire lengths to the nearest $1.3 \mathrm{\mu m}$, the process of mounting the end of the wire in its fixture can produce errors in the wire length measurement to $\pm 50 \mathrm{~m}$. Because the sequentially cut wires generally differ in length by $\sim 5 \mathrm{~mm}$, the uncertainty in the velocity measurement due to this length uncertainty is approximately $\pm 1 \%$. Immediately upon experiment recovery in an underground test, a $7 \mathrm{X}$ magnifying glass and scale are used for preliminary wire length measurements. These results generally agree to within $\pm 5 \%$ with the later, more precise laboratory measurements. Both portions of the cut wire are measured in each method.

By performing a least-squares fit of the wire length data to the rotor calibration data, the velocity of the sliding assembly and hence the impulse imparted to the sample cup, is obtained. The fitting procedure allows for the use of any number of reasonable wire lengths up to seven. The computer code produces a plot of rotor position vs time (see Fig. 13), and a printout containing the slope of the curve, its intercept, and the errors in the slope and intercept. A statistical average of the velocity obtained from both the front wires and back wires is also provided. For impulses above $0.1 \mathrm{~N} \cdot \mathrm{B}$, the statistical goodness of fit is generally less than one-half a standard deviation, producing impulse data that are good to approximately $\pm 5 \%$. Below this value, frictional effects play an increasingly important role as they do in the active 


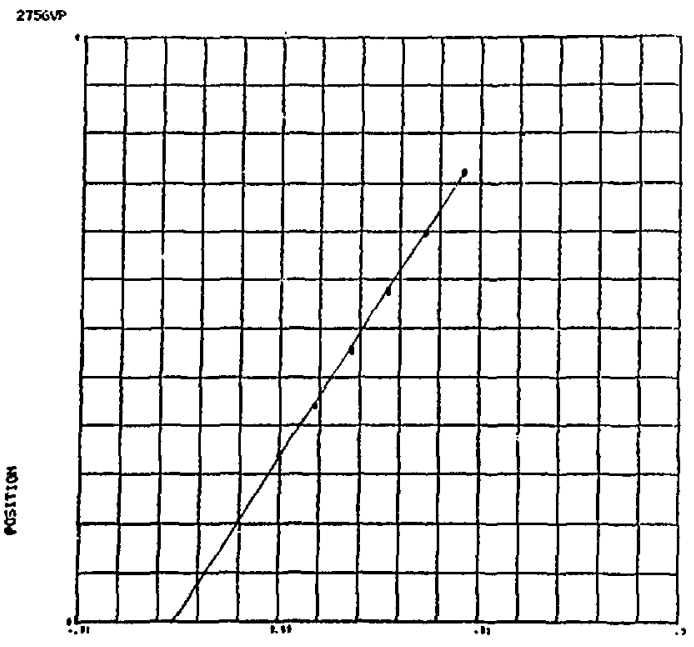

Tine

Fig. 13. Computer plot of position vs time for passive wirecutter data from a recent underground test.

part of the gauge. Uncertainties in rotor performance due to the rotor not cutting wires during the calibration procedure are negligible.

\section{SUMMARY}

To our knowledge the Combination Impulse Transducer represents the first recorded attempt to comblne two equally reliable, but entirely different, methods of impulse measurement into a single, compact, instrument package. The active part, adopted from the Probe Velocity Trangducer, has a useful range from $0.02 \mathrm{~N} \cdot \mathrm{s}$ to $40 \mathrm{~N} \cdot \mathrm{s}$, whereas the passive wirecutter part has a useful range from $0.01 \mathrm{~N} \cdot \mathrm{s}$ to $2.5 \mathrm{~N} \cdot \mathrm{s}$. An independent, external rotor triggering mechanism makes this low Impulse threshold possible. The active part is relatively insensitive to nuclear radiation damage (see Ref. 1), and the passive part provides Impulse measurement prior to ground shock arrival. The characteristic shape and relatively low frequency $(5 \mathrm{kHz}$ ) of the output signal simplifies reduction of the test data and permits the use of low quality cable for signal transmission to distant recording factlities. The gauge also lends itself to use in multiple cassettes, thereby simplifying alignment procedures and maxtmizing the aval1able beam area.
Figure 14 is an active signal recorded in a recent underground nuclear test. An Ampex model 1400 tape deck with a frequency response of dc to $20 \mathrm{kHz}$ was used for signal recording. Because the primary consideration in data recording is the relative times of change in the signal level as each ring passes through the pickup coll, signal amplitude varlations produced by radiation of the pickup coil and electronics are not of major concern.

\section{ACKNOWLEDGEMENTS}

The authors acknowledge the valuable assistance of the other members of LASL Group WX-6 in developing the gauge. Particular thanks are due P. E. Barbo, J. E. Johnson, R. J. Lanter, and B. E. Todd for their help and cooperation. The special air gun for gauge calibration was designed by P. E. Barbo.

\section{REFERENCES}

1. V. S. Starkovich, B. E. Todd, E. L. Stephani, and E. V. Hawkins, "Probe Velocity Transducer," Los Alamos Scientific Laboratory Report LA-4999. MS (Sept. 1972).

2. L. M. Fitzgerald and J. M. Polastri, "Design and Development of Active Backup Gage for Wire Cutter Impulse Gage," Philco-Ford Corp., Report TR-73-79 (January 1973).

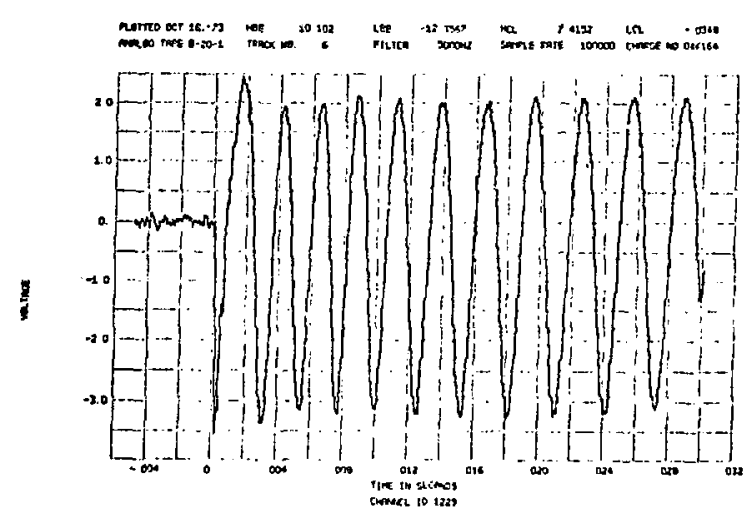

owis wo tas

F1g. 14. Active signal record from a CIT gauge fielded on a recent underground test. 